\title{
An Overview of Confidence in Diabetes Self- Management among Diabetics in the State of Qatar
}

\author{
Al-Anoud M Al-Thani ${ }^{1}$, Aiman Hussein Farghaly ${ }^{1 *}$, Shams Eldin Khalifa ${ }^{1}$, Hammad Akram ${ }^{1}$, Benjamin Vinodson \\ Poovelil ${ }^{1}$, Alma Malvar Loares ${ }^{1}$ and Abdul Badi Abou-Samra ${ }^{2}$
}

${ }^{1}$ Public Health Department, Ministry of Public Health, Qatar

${ }^{2}$ Department of Medicine, Hamad Medical Corporation, Qatar

Submission: November 16, 2018; Published: January 11, 2019

*Corresponding author: Aiman Hussein Farghaly, Public Health Department, Ministry of Public Health, Doha, Qatar

\section{Abstract}

Background: Diabetes complications are preventable given a supportive environment. Managing diabetes daily requires confidence which can be effectively done with effective support system. The information and health services received by diabetics are vital to empowerment as it enables them to make correct choices for better outcomes. The aims of this study were to examine patients' confidence in self-managing diabetes and its relationship to the level of information and available diabetes related services received in the State of Qatar.

Methods: The study was conducted among 300 diabetic patients through face-to-face interviews using a semi-structured questionnaire between February and May 2015 at healthcare facilities of Hamad Medical Corporation in Qatar. Patient consent to participate was sought Survey responses were analyzed using frequencies, percentages, Chi-squared and Fisher's exact tests at $5 \%$ level of significance.

Results: About $54 \%$ of patients reported to have had Type 2 and $31 \%$ had Type 1 diabetes. Approximately $32 \%$ were treated for complications. Diabetic patients were more likely to gain confidence in managing their diabetes the more frequent they were in contact with hospital specialist consultant $(\mathrm{P}=.02)$, foot specialist $(\mathrm{P}=.03)$, eye specialist $(\mathrm{P}=.03)$ and diabetes coordinator $(\mathrm{P}<0.000)$, when provided with diabetes plan $(\mathrm{P}$ $<, 000)$, and having a contact number to call for any diabetes-related concern $(\mathrm{P}=, 005)$. Healthcare services available to the patients were a significant help for diabetic patients in coping and confidently managing their diabetes.

Conclusion: Better patient-provider collaboration and healthcare system's provision of medical services were substantially useful to diabetics in developing higher confidence to self-manage diabetes.

Keywords: Diabetes self-management; Diabetes; Qatar; Patient-Provider collaboration; Diabetic patient survey; Self-managing diabetes; Diabetes knowledge; Diabetes health services

Abbreviations: T1D: Type 1 Diabetes; T2D: Type 2 Diabetes; MOPH: Ministry of Public Health; NHS: National Health Strategy; NDS: National Diabetes Strategy; NHANES: National Health and Nutrition Examination Survey; HMC: Hamad Medical Corporation; PHCC: Primary Healthcare Corporation; BMI: Body Mass Index

\section{Introduction}

Diabetes is a health challenge as it has tremendous impact on the population's quality of life and well-being. Diabetes complications and its comorbidities contribute to increased death rates. NHS reported that $7 \%$ of mortalities in Qatar were caused by diabetes and related complications [1]. National survey conducted in 2012 among Qataris found that the prevalence of diabetes among adult population was $16.7 \%$ in both sexes. Proportion of overweight individuals was at $70.1 \%$, hypertensive individuals were $33 \%$ while obesity was at $41.4 \%$ [2]. This high incidence of diabetes precipitated from the rapid socio-economic development in the country which led to low physical activity, unhealthy food choices and obesity.

Qatar's average yearly healthcare expenditure on diabetes treatment and its complications was estimated at QR1.8bn and projected to increase to QR $4.9 \mathrm{bn}$ by 2035 , with a corresponding rise in the number of diabetics to 299,000 at same year [3]. If the diabetes menace is left uncontrolled, it would adversely impact not only the country's economic progress but also the individual's quality of life. Through the National Diabetes Strategy (NDS), which is a component of Qatar's National Health Strategy (NHS), it targets to decrease the incidence and complications of diabetes by raising public awareness through health promotion approaches, education and counselling [4].

Serious complications of diabetes are preventable if people with diabetes understand their disease and participate in managing their own care $[5,6]$. It is imperative to focus prevention efforts in combating diabetes which involve both patients' and healthcare providers. Accordingly, the individual level knowledge 
about the diseases will be more valuable if supplemented by readily available effective and affordable healthcare services [4]. Many studies emphasized effective strategies in improving diabetes care such as patient education and support, provider role through multidisciplinary teams, and telemedicine [7]. Moreover, supportive services such as nutrition counselling, health education, family and workplace engagement are essential in empowering patients to manage their diabetes [8].

An overview of Qatar's healthcare support facilities and professionals shows that the country has 302 healthcare centers/ clinics, 61 diagnostic facilities and 251 pharmacies, as of 2014 [9], The inpatient services in Qatar are provided by 13 hospitals (consisting of 8 public hospitals of Hamad Medical Corporation (HMC) and 5 private facilities) while the outpatient services are catered by the Primary Healthcare Corporation (PHCC), other government-operated health centers and private clinics in the country [9]. Various endocrinology and diabetes clinics were opened in the entire country to provide comprehensive and interdisciplinary care to both children and adult diabetic patients. In terms of healthcare manpower, the rate of physicians in Qatar is 3.1 per 1000 population, 5.8 nurses per 1000 population, 0.09 pharmacists per 1000 population, 0.7 dentists per 1000 population and 3.6 per 1000 population for other healthcare providers [10].

The Supreme Council of Health (now Ministry of Public Health) commissioned a survey in 2015 through the YouGOv UK (a market research organization) to understand the diabetes situation in Qatar and to improve the awareness and education of both the patients and general population about diabetes. The current study presents the results obtained from this survey about the perceptions of diabetic patients who sought medical care at the local hospitals and healthcare facilities in Qatar. The study primarily aimed to gauge the level of diabetes-related support diabetic patients received from the healthcare providers and determine the former's confidence in managing their disease. The study presents the characteristics of the diabetic patients, their knowledge of diabetes-related factors, and their perception on the diabetes related services in the State of Qatar. This study supports the Qatar National Health Strategy (NHS) and National Diabetes Strategy (NDS) in preventing complications, monitoring and educating patients and the general public about diabetes, related factors, and preventive approaches [4].

\section{Methods}

The data in this report was sourced from the survey conducted among diabetic patients attending their appointments Table 1: Characteristics of study respondents. at the outpatient clinics of Hamad Medical Corporation (HMC). HMC is a major public non-profit healthcare provider composed of nine tertiary hospitals and various clinics offering about $90 \%$ of acute services in the State of Qatar [11]. Through purposive sampling, a quota of 300 patients were selected and approached by the trained surveyors in the waiting areas or walk-in rooms of pediatric and adult diabetes clinics, women's clinic, foot clinic and renal center, Sample quota was categorized based on the population characteristics in Qatar [12]. The 20-30-minute survey was carried out using a pre-tested and validated English and Arabic translated semi-structured questionnaire during the clinics' regular working hours in February and May of 2015. Inclusion criteria for recruitment were Qatar residents (Qatari and Non-Qatari nationals), both sexes, at least 16 years with diabetes. On the other hand, visitors and non-resident of Qatar, less than 16 years old and without diabetes were excluded from the study. Patient participation in the survey was on voluntary basis, with informed consent obtained prior to survey and patients were assured of data confidentiality. Parental consent was sought for patient respondents below 18 years old. The study was approved by the Supreme Council of Health, Doha, Qatar.

Questions included were related to patients' characteristics, knowledge about diabetes-related factors, associated complications and diabetes service level support received from health facilities, health providers, and other local diabetes support groups. The patients' perception of diabetes and related factors were evaluated by Likert scale questions using a 5 -point scale (nothing, very little, some, enough, and a lot) at 95\% confidence interval. Frequencies, percentages, Chi-squared and Fisher's exact tests were used to present and analyze the data. Data processing and analyses were carried out using the SPSS Software version 22.0 (IBM Corporation, Chicago, IL, USA) at $5 \%$ level of significance.

\section{Results}

\section{Respondents' characteristics}

The respondents' profile were characterized in terms of patients' age, gender, nationality group and marital status. Among the 300 respondents, the highest percentage was in the age group 35-54 years $(n=123,41 \%)$ and least among 16-24 years $(n=20,6.7 \%)$. Proportion of males $(n=166,55.3 \%)$ were slightly higher than females $(n=134,44.7)$. Highest percentage of participants were Arab expatriates ( $n=110,36.7 \%)$ and least among Westerners $(n=10,3.3 \%)$. Majority of the respondents were married with children $(n=240,80 \%)$ while widowed or divorced $(13,4.3 \%)$ were least represented (Table 1).

\begin{tabular}{|c|c|}
\hline Characteristics & n (\%) \\
\hline $\mathrm{N}$ & \multicolumn{2}{|c|}{300} \\
\hline \multicolumn{2}{|c|}{ Age } \\
\hline $16-24$ years & $20(6.7)$ \\
\hline $25-34$ years & $72(24.0)$ \\
\hline
\end{tabular}




\section{Current Research in Diabetes \& Obesity Journal}

\begin{tabular}{|c|c|}
\hline $35-54$ years & $123(41.0)$ \\
\hline 55-64 years & $58(19.3)$ \\
\hline 65 years and above & $27(9.0)$ \\
\hline \multicolumn{2}{|c|}{ Gender } \\
\hline Male & $166(55.3)$ \\
\hline Female & $134(44.7)$ \\
\hline \multicolumn{2}{|c|}{ Nationality Group } \\
\hline Qatari nationals & $88(29.3)$ \\
\hline Arab expatriates & $110(36.7)$ \\
\hline Asian & $92(30.7)$ \\
\hline Westerner & $10(3.3)$ \\
\hline \multicolumn{2}{|c|}{ Marital Status } \\
\hline Single & $29(9.7)$ \\
\hline Married with children & $240(80.0)$ \\
\hline Married without children & $18(6.0)$ \\
\hline Widowed/ divorced & $13(4.3)$ \\
\hline
\end{tabular}

\section{Diabetes types and diagnosis related factors}

Table 2 presents respondents' characteristics by type and diagnosis of diabetes. More than half of the respondents (53.7\%) self-reported having Type 2 Diabetes (T2D); 31\% have had Type 1 Diabetes (T1D); and the rest have not specified their type of diabetes or were not aware of the type. The median duration of diabetes (all types) among sample was 60 months which indicated that half of the patients surveyed had diabetes duration above and below 60 months. Approximately $32 \%$ of respondents stated that they were treated for diabetes-related complications such as high cholesterol (39\%), vision problems (33\%), hypertension (30\%) and foot problems (25\%) as among the most common. Most of the respondents were diagnosed at primary care clinics (41.7\%). Regarding the health information received at the time of diagnosis, approximately $44 \%$ acknowledged that they received the right amount of diabetes-related information. Almost half of the respondents $(49.3 \%)$ received diabetes-related brochures at the time of diagnosis and majority of them were either satisfied $(63.5 \%)$ or extremely satisfied $(27 \%)$ with the information contained in it. Majority of the respondents (78.3\%) were fully advised regarding the different types of diabetes tests.

Table 2: Respondents' characteristics by diabetes types and diagnosis related factors.

\begin{tabular}{|c|c|}
\hline & n (\%) \\
\hline $\mathrm{N}$ & 300 \\
\hline \multicolumn{2}{|c|}{ Diabetes Type } \\
\hline $\mathrm{T} 1 \mathrm{D}$ & $93(31.0)$ \\
\hline $\mathrm{T} 2 \mathrm{DM}$ & $161(53.7)$ \\
\hline Others/ unspecified & $46(15.3)$ \\
\hline \multicolumn{2}{|l|}{ Duration of diabetes } \\
\hline Months [Median(IQR)] & $60(24,144)$ \\
\hline \multicolumn{2}{|c|}{ Treated with Complications } \\
\hline Yes & $97(32.3)$ \\
\hline No & $203(67.7)$ \\
\hline \multicolumn{2}{|c|}{ Diabetes-Related Complications* } \\
\hline High cholesterol & $117(39.0)$ \\
\hline Vision problems & $99(33.0)$ \\
\hline High blood pressure & $90(30.0)$ \\
\hline Foot problems & $75(25.0)$ \\
\hline Kidney problems & $24(8.0)$ \\
\hline Dental bleeding & $21(7.0)$ \\
\hline
\end{tabular}




\section{Current Research in Diabetes \& Obesity Journal}

\begin{tabular}{|c|c|}
\hline Osteoporosis & $18(6.0)$ \\
\hline Heart problems & $12(4.0)$ \\
\hline \multicolumn{2}{|c|}{ Location of Diagnosis } \\
\hline Screening bus & $6(2.0)$ \\
\hline Primary care & $125(41.7)$ \\
\hline Diabetes clinic & $39(13.0)$ \\
\hline Emergency room & $51(17.0)$ \\
\hline Women's hospital & $23(7.7)$ \\
\hline Professional test following a self-test & $38(12.7)$ \\
\hline Other & $18(6.0)$ \\
\hline \multicolumn{2}{|c|}{ Level of Information at First Time of Diagnosis } \\
\hline Too little information & $113(37.7)$ \\
\hline Received right amount of information & $133(44.3)$ \\
\hline Received too much information & $32(10.7)$ \\
\hline Don't know/ can't remember & $22(7.3)$ \\
\hline \multicolumn{2}{|c|}{ Brochures on Diabetes at Time of Diagnosis } \\
\hline Yes & $(49.3) 148$ \\
\hline No & $146(48.7)$ \\
\hline Don't know & $6(2.0)$ \\
\hline \multicolumn{2}{|c|}{ Satisfied with Brochures } \\
\hline Extremely dissatisfied & $3(2.1)$ \\
\hline Dissatisfied & - \\
\hline Neither satisfied/ dissatisfied & $11(7.4)$ \\
\hline Satisfied & $94(63.5)$ \\
\hline Extremely satisfied & $40(27.0)$ \\
\hline \multicolumn{2}{|c|}{ Fully Advised on all of Diabetes Tests } \\
\hline Yes & $235(78.3)$ \\
\hline No & $46(15.3)$ \\
\hline Don't know/ can't remember & $19(6.3)$ \\
\hline
\end{tabular}

\section{Treatment planning}

Table 3 shows patients' behaviour as regards follow-up visits and treatment planning. More than half of the diabetics (57\%) had four or more visits for their disease-related check-ups in past 12 months. Majority of patients received diabetes-related guidance from a physician $(89.7 \%)$ while more than half received valuable advice and support from the nurses (69.3\%). Among the $56 \%$ who have at least worked with the health professionals for goal setting, a lower percentage of $22.3 \%$ did goal setting with the health professionals in every visit while $33.7 \%$ sometimes or to some extent did treatment planning during their visit with healthcare team. Less than half of patients reported that they received sufficient advice from the clinic staff regarding diet (34.3\%) and physical activity (42.7\%) while others did receive but not enough or not at all. About $57 \%$ of patients affirmed that they were provided with a copy of diabetes plan during their last visit and according to $95 \%$ of these respondents, the plan usually included next appointment time and date. It can be noted that over $64 \%$ of the patients felt confident or very confident in managing their diabetes themselves as a result of their diabetes follow up visits during the past 12 months. Most of the respondents stated that they underwent diabetes relevant tests such as body mass index (BMI) (79.3\%), blood pressure (78\%), cholesterol (69.3\%), HbA1c (68\%) and others during the past 12 months. Approximately $62 \%$ acknowledged that the results of these tests were fully explained to them.

Table 3: Follow up Visits \& Treatment Planning.

\begin{tabular}{|c|c|}
\hline & n (\%) \\
\hline Diabetes follow up visits in the past 12 months & $26(8.7)$ \\
\hline Once & $39(13.0)$ \\
\hline Twice
\end{tabular}




\section{Current Research in Diabetes \& Obesity Journal}

\begin{tabular}{|c|c|}
\hline Three times & $42(14.0)$ \\
\hline Four times or more & $171(57.0)$ \\
\hline \multicolumn{2}{|c|}{ Received advice and guidance in relation to diabetes } \\
\hline Doctor & $269(89.7)$ \\
\hline Nurse & $5(1.7)$ \\
\hline Support groups & $2(0.70)$ \\
\hline Friends & $2(0.70)$ \\
\hline Family & $9(3.0)$ \\
\hline Dietician & $6(2.0)$ \\
\hline Personal trainer & $2(0.70)$ \\
\hline Others & $3(1.0)$ \\
\hline Nobody & $2(0.70)$ \\
\hline \multicolumn{2}{|c|}{ Value of advice and support provided by nurse } \\
\hline Yes & $208(69.3)$ \\
\hline No & $57(19.0)$ \\
\hline \multicolumn{2}{|c|}{ Worked with the health professionals to set goals about the best way to manage diabetes } \\
\hline Yes, completely each time I visit them & $67(22.3)$ \\
\hline Yes, to some extent-sometimes at visit & $101(33.7)$ \\
\hline No, but I would have liked to & 77 (25.7) \\
\hline \multicolumn{2}{|c|}{ Received advice to change diet that could help manage diabetes } \\
\hline Yes, definitely & $103(34.3)$ \\
\hline Yes, to some extent but not enough & $(27.3) 82$ \\
\hline No, but I would have liked help/advice & $56(18.7)$ \\
\hline \multicolumn{2}{|c|}{ Received advice on physical activity from clinic staff } \\
\hline Yes, definitely & $128(42.7)$ \\
\hline Yes, to some extent but not enough & $63(21.0)$ \\
\hline No, but I would have liked help/advice & $42(14.0)$ \\
\hline \multicolumn{2}{|c|}{ Thinking back to your last visit, were you given a copy of your diabetes plan? } \\
\hline Yes & $172(57.3)$ \\
\hline No & 119 (39.7) \\
\hline \multicolumn{2}{|c|}{ Diabetes plan includes any of the following: } \\
\hline Your next appointment time and place & $164(95.3)$ \\
\hline Name of contact person & $71(41.3)$ \\
\hline Info. on managing diabetes between appointments & $56(32.6)$ \\
\hline Personal goal and targets about diabetes & $43(25.0)$ \\
\hline Advice on your diet and what foods to eat & $67(38.9)$ \\
\hline Advice on physical activity & $51(29.6)$ \\
\hline Your results of the diabetes tests & $92(53.5)$ \\
\hline A plan for medicines \& lifestyle & $91(52.9)$ \\
\hline Your health information \& diabetes status & $45(26.7)$ \\
\hline \multicolumn{2}{|c|}{ Confidence in managing diabetes due to the health check-up in past 12 months } \\
\hline Very confident & $60(20.0)$ \\
\hline Confident & $134(44.7)$ \\
\hline Not sure & $77(25.7)$ \\
\hline Fairly unconfident & $20(6.7)$ \\
\hline
\end{tabular}




\section{Current Research in Diabetes \& Obesity Journal}

Very unconfident

$9(3.0)$

In the last 12 months, have you undergone any of the following diabetes related tests? (Yes/No)

\begin{tabular}{|c|c|}
\hline In the last $\mathbf{2}$ months, have you undergone any of the following diabetes related tests? (Yes/No) \\
\hline Weight/ Body Mass Index (BMI) & $238(79.3)$ \\
\hline Blood Pressure & $234(78.0)$ \\
\hline Cholesterol & $208(69.3)$ \\
\hline HbA1c (long term blood glucose test) & $204(68.0)$ \\
\hline Blood test for kidney function & $158(52.7)$ \\
\hline Urine test & $220(73.3)$ \\
\hline Foot examination & $140(46.7)$ \\
\hline Eye screening & $161(53.7)$ \\
\hline Don't know/ can't remember & $8(2.7)$
\end{tabular}

Were the results of these tests fully explained to you? (B14)

\begin{tabular}{c|c} 
Yes, and I understood them clearly & $181(61.9)$ \\
Yes, But I did not really understand them & $26(8.9)$ \\
No, I didn't need them to be & $41(14.2)$ \\
No, not at all & $22(7.5)$ \\
Don't know/ can't remember & $22(7.5)$
\end{tabular}

\section{Diabetes knowledge}

Patients' understanding of the different diabetes dimensions and related factors were evaluated by Likert scale questions, responses of which were shown in Table 4. Majority of respondents indicated that they have at least "some" or "enough" knowledge about most of the factors influencing diabetes. More than half indicated that they have been "enough" or "a lot" informed about the importance of having a regular visit with the doctor or nurse (65.3\%). However, more than half had no idea about the effect or relation of drinking alcohol (58\%) and smoking (53.3\%) to diabetes while a greater proportion of them had no $(33 \%)$ or very little knowledge $(14.7 \%)$ about the adverse effects of taking medications.

Table 4: Respondents' extent of understanding on diabetes-related factors.

\begin{tabular}{|c|c|c|c|c|c|c|c|c|c|c|}
\hline & $\begin{array}{l}\text { Noth- } \\
\text { ing }\end{array}$ & $\%$ (CI\%) & Very little & $\%(C I \%)$ & Some & $\%(\mathrm{CI} \%)$ & Enough & $\%(\mathrm{CI} \%)$ & A lot & $\%(\mathrm{CI} \%)$ \\
\hline $\begin{array}{l}\text { The effects of being ill: } \\
\text { ex. Having flu }\end{array}$ & 29.7 & $(24.8,35.1)$ & 16.7 & $(12.9,21.3)$ & 29.7 & $(24.8,35.1)$ & 16.7 & $(12.9,21.3)$ & 7.2 & $(4.9,10.8)$ \\
\hline Maintaining weight & 17 & $(13.2,21.7)$ & 16.3 & $(12.6,20.9)$ & 25.3 & $(20.7,30.5)$ & 28.3 & $(23.5,33.6)$ & 13.1 & $(9.7,17.3)$ \\
\hline $\begin{array}{l}\text { Blood glucose drops } \\
\text { too low }\end{array}$ & 5.7 & $(3.6,8.9)$ & 21.7 & $(17.4,26.7)$ & 31.7 & $(26.7,37.1)$ & 25 & $(20.4,30.2)$ & 16 & $(12.3,20.6)$ \\
\hline $\begin{array}{l}\text { Regular check-ups with } \\
\text { doctor/ nurse }\end{array}$ & 4 & $(2.3,6.7)$ & 8.7 & $(6.0,12.4)$ & 22 & $(17.7,27.0)$ & 37 & $(31.7,42.7)$ & 28.3 & $(23.5,33.7)$ \\
\hline Cholesterol levels & 20 & $(15.9,24.9)$ & 17.3 & $(13.5,22.0)$ & 27 & $(22.3,32.3)$ & 28 & $(23.2,33.3)$ & 7.7 & $(5.2,11.2)$ \\
\hline Blood pressure & 19.7 & $(15.6,24.5)$ & 17.7 & $(13.8,22.4)$ & 29.7 & $(24.8,35.0)$ & 24.7 & $(20.1,29.8)$ & 8.3 & $(5.7,12.0)$ \\
\hline $\begin{array}{l}\text { Checking and looking } \\
\text { after eyes }\end{array}$ & 18 & $(14.1,22.7)$ & 12.7 & $(9.4,16.9)$ & 28.7 & $(23.8,34.0)$ & 19.3 & $(15.3,24.2)$ & 21.3 & $(17.1,26.3)$ \\
\hline $\begin{array}{l}\text { Checking and looking } \\
\text { after feet }\end{array}$ & 21.3 & $(17.1,26.3)$ & 18.7 & $(14.7,23.5)$ & 26.3 & $(21.7,31.6)$ & 22 & $(17.7,27.0)$ & 11.7 & $(8.5,15.8)$ \\
\hline Drinking alcohol & 58 & $(52.3,63.4)$ & 6 & $(3.8,9.3)$ & 9.7 & $(6.8,13.5)$ & 11.3 & $(8.2,15.4)$ & 15 & $(11.4,19.5)$ \\
\hline Smoking & 53.3 & $(47.7,58.9)$ & 4 & $(2.3,6.8)$ & 17.7 & $(13.8,22.4)$ & 11 & $(7.9,15.0)$ & 14 & $(10.5,18.4)$ \\
\hline Stress & 10.3 & $(7.4,14.3)$ & 22.7 & $(18.3,27.7)$ & 36 & $(30.8,41.6)$ & 18.7 & $(14.7,23.5)$ & 12.3 & $(9.1,16.5)$ \\
\hline Tiredness & 9.3 & $(6.5,13.1)$ & 19.3 & (15.3, & 24.2 & $(31.4,42.3)$ & 23.7 & $(19.2,28.3)$ & 11 & $(7.9,15.0)$ \\
\hline $\begin{array}{l}\text { Adverse effects taking } \\
\text { medication }\end{array}$ & 33 & $(27.9,38.5)$ & 14.7 & $(11.1,19.1)$ & 23.3 & $(18.9,28.4)$ & 17 & $(13.2,21.7)$ & 12 & $(8.8,16.2)$ \\
\hline $\begin{array}{l}\text { Severe complications } \\
\text { left untreated }\end{array}$ & 8 & $(5.4,11.6)$ & 15.3 & $(11.7,19.8)$ & 31.1 & $(26.0,36.4)$ & 22.3 & $(17.9,27.4)$ & 23.3 & $(18.9,28.4)$ \\
\hline
\end{tabular}




\section{Current Research in Diabetes \& Obesity Journal}

Respondents' level of confidence in diabetes self-management and local support received

The patients' confidence in managing their diabetes was correlated with some of the related services and support they received within the country. Table 5 emphasizes the significant role of support provided by the healthcare providers to the patients' level of confidence in managing their diabetes. More than half of the participants have sufficient contact with the doctor $(78 \%)$ and nurse $(58 \%)$ at local clinics. It was more likely for patients to be more confident in self-managing their diabetes care the more frequent they get in contact with the hospital specialist consultant $(\mathrm{P}=.02)$, foot specialist $(\mathrm{P}=.03)$, eye specialist $((\mathrm{P}=.03)$ and diabetes coordinator $(\mathrm{P}<.000)$. These healthcare providers were perceived by the diabetics as the most significant providers of diabetic care as their contact with them were substantially helpful in gaining confidence to manage their disease. Moreover, patients who were given a copy of their diabetes plan during their last check-up $(\mathrm{P}<0.000)$ and having a contact number to call for any diabetes-related concern $(\mathrm{P}=0.005)$ were more likely to be confident in managing their disease (Table 6). The diabetes plan provided patients' next appointment time and date, the contact person, information on managing diabetes between appointments, personal goals and targets about diabetes, advice on diets and physical activity, results of diabetes tests, a plan for medicines and lifestyle and other health information and diabetes status. Only a quarter of the patients were given or knew the hotline number to contact in cases of diabetes-related queries. Patients found it very essential that they have available channels of communicating their concerns and receiving diabetes information that would support in better self-managing their disease.

Table 5: Relation between Patient's Level of Confidence in Diabetes Self-Management and Extent of Contact with Health Professionals.

\begin{tabular}{|c|c|c|c|c|c|c|}
\hline \multirow{2}{*}{ Health Professionals } & \multicolumn{5}{|c|}{ Extent of Contact with Health Professionals } & \multirow{2}{*}{ P-value* } \\
\hline & Too little n (\%) & A little n (\%) & Right amount n (\%) & $A \operatorname{lot} n(\%)$ & $\begin{array}{c}\text { Too much } \\
\text { n (\%) }\end{array}$ & \\
\hline Doctor at local clinic & $41(14)$ & $25(8)$ & $88(29)$ & $63(21)$ & $83(28)$ & 0.19 \\
\hline Nurse at local clinic & $85(28)$ & $40(13)$ & $98(33)$ & $53(18)$ & $24(8)$ & 0.39 \\
\hline Specialist consultant at hospital & $122(41)$ & $54(18)$ & $90(30)$ & $16(5)$ & $18(6)$ & $.02 *$ \\
\hline Specialist nurse at hospital & $156(52)$ & $68(23)$ & $49(16)$ & $14(5)$ & $13(4)$ & 0.21 \\
\hline Foot specialist & $127(42)$ & $60(20)$ & $74(25)$ & $21(7)$ & $18(6)$ & $.03 *$ \\
\hline Eye specialist & $89(30)$ & $67(22)$ & $73(24)$ & $30(10)$ & $41(14)$ & $.03 *$ \\
\hline Dietician & $135(45)$ & $65(22)$ & $67(22)$ & $19(6)$ & $14(5)$ & 0.8 \\
\hline Diabetes Coordinator & $192(64)$ & $29(10)$ & $67(22)$ & $2(1)$ & $10(3)$ & $<.000^{*}$ \\
\hline
\end{tabular}

Table 6: Relation between patients' level of confidence in diabetes self-management and diabetes-related services/support received.

\begin{tabular}{|c|c|c|}
\hline Diabetes-related Services \& Support Received & n (\%) & P-value \\
\hline Fully advised on all of the diabetes tests that patients required to have & $235(78)$ & 0.47 \\
\hline Given a copy of your diabetes plan during patient's last check-up & $172(57)$ & $<.000^{*}$ \\
\hline Provided with brochures on diabetes at the time of diagnosis & $148(49)$ & 0.15 \\
\hline Contact number to call for any diabetes-related concern & $76(25.3)$ & $.005^{*}$ \\
\hline
\end{tabular}

\section{Information and communication support}

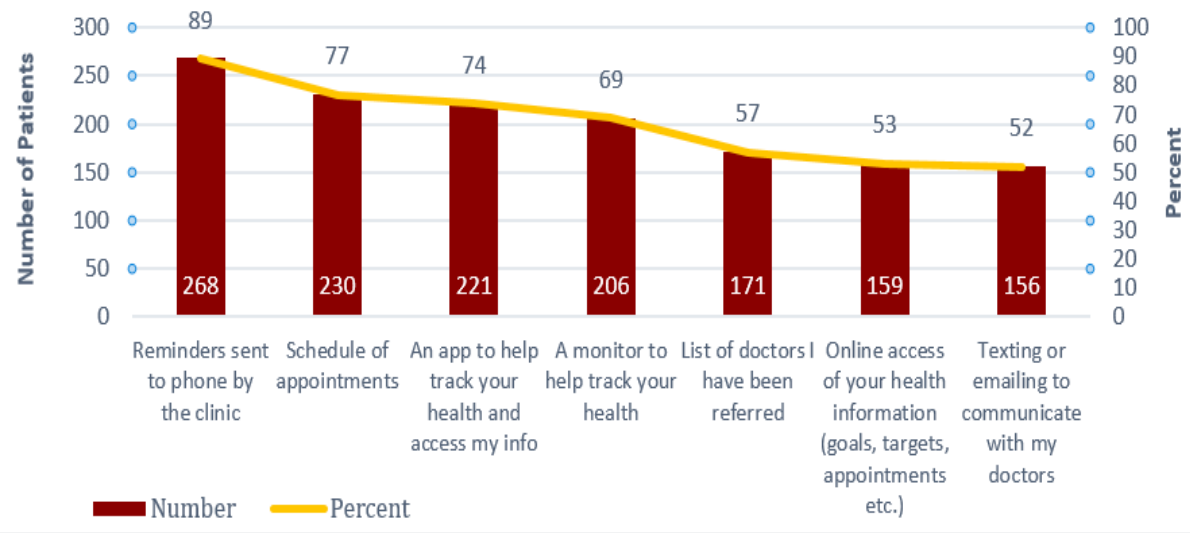

Figure 1: Patients preference of diabetes-related information or communication services. 


\section{Current Research in Diabetes \& Obesity Journal}

Respondents were asked of their preference for diabetesrelated information and communication services that they wished to receive in the future to provide them with better service. Patients mostly preferred SMS reminders sent to patient's phone by the clinic (89\%), their schedule of appointments (77\%), an app to help track health and access health information (74\%), a monitor to help track own health (69\%), and list of doctors that patients have been referred to (57\%) as among the top 5 responses (Figure 1). Patients found these forms of communication as particularly useful because they were more likely to develop self-efficacy after gaining knowledge about their health conditions, diabetes treatment plans and access to healthcare services. When patients understand the burden of their disease, they are motivated more to actively participate in managing their own care with the healthcare professionals.

\section{Discussion}

This study provided an overview of the diabetes-related services and information received by the patients from the healthcare professionals and Qatar's healthcare facilities in developing their confidence to self-manage their disease. A third of the respondents surveyed were treated for the diabetes-related complications due to all types of diabetes. According to the National Health and Nutrition Examination Survey (NHANES), 1999-2004 (USA), the prevalence of diabetes complications among diabetics were mainly due to retinopathy (18.9\%), foot problems $(22.9 \%)$ and kidney disease $(27.8 \%)$ [13]. In a Saudi review article, the prevalence of retinopathy was found to be $31 \%$ while neuropathy and foot disease was alarmingly high (82\%) along with kidney disease was identified as an important complication of diabetes [14]. At least half of the patients received adequate information during the first time of diagnosis while a significant proportion (45\%) reported that the level of information they received during this encounter was either too little or cannot be remembered. Moreover, almost half of the patients (49\%) received brochures from the healthcare facility at the time of diagnosis, and about $90 \%$ of them were happy with the contents. These findings provide a valuable information to this study because patient satisfaction in most healthcare services predicts the quality of care and the management required from the health providers [15].

Most of the patients received additional examination and testing relating to their diabetes diagnosis which includes body mass index (BMI), blood pressure, urine testing, cholesterol \& HbA1c etc. About $62 \%$ of the patients confirmed that these results were effectively explained to them. After 12 months of diabetes checkups, at least $67 \%$ of patients felt confident in managing their disease appropriately. This was attributed to the valuable support provided by the health practitioners, and the health care services made available to the patients. In terms of patient-provider relationship, majority of patients received guidance from their doctors. As expected, most patients cited doctors as their primary source of knowledge about their disease.

The extent of patient-provider communication and treatment planning significantly correlated with increased confidence of di- abetics to self-manage their diabetes. In terms of communication, found that the respondents were fairly able to work with healthcare professionals in setting goals on the best ways to manage their diabetes. These factors are important since it is evident that lack or insufficient communication between provider and patient with diabetes could lead to poor compliance among patients $[16,17]$.

Furthermore, the patients who less frequently receive information about diabetes are also less likely to manage their disease themselves [18]. In the present study, patients who underwent proper checkups in past 12 months, were provided a copy of their diabetes plan, had a contact number to call for any diabetes-related concern, had more frequent contact with the health professionals were confident about diabetes selfmanagement. Also, the majority of them were satisfied with the contents of the brochures provided to them at the time of diagnosis. While participants understood well regarding the importance of relationship with healthcare providers, family members and other people with diabetes as a support, the greater proportion of them were not aware of any local diabetes advocacy group. In another study the participants also considered patient-provider collaboration, positive attitude among them, having a support person in their lives, and participation in group educational activities as essential components of an effective diabetes selfmanagement strategy [19].

Studies reveal that patients are more likely to develop confidence after gaining knowledge of their own health conditions, treatment plans and health care access. Confidence motivates and empowers patients to communicate with health providers, express their concerns and preferences [20,21]. Patients understanding of the burden of their disease is important in developing preventive strategies and bringing patients to collaboratively manage care with the health professionals. Collaborative relationship between the health care providers and patients brings effective diabetes care through achieving improved outcomes and a higher level of satisfaction [22].

Most patients preferred reminders sent to patient's phone by the clinic (89\%) as a way of communicating diabetes-related information. This information provides our healthcare providers and policy makers evidence on the best ways to reach and help diabetic patients in accessing information to better manage their disease. Enhancing patient-provider communication and shared decision making have been shown to result in greater patient satisfaction, adherence to treatment plans, and improved health outcomes. Collecting patient experience information and timely provision of relevant information to patients builds their capacity to actively manage their own care through behavioral change and adherence to treatment plan [23,24]. A greater percentage of the respondents had at least some understanding about their diagnosis and disease such as their glucose levels, cholesterol levels, blood pressure and things such as maintaining weight, having regular check-ups, checking their feet, and other related factors etc. On the other hand, more than half had nothing or very 
little understanding about selected factors such as alcohol use, smoking, and medicine side effects. Although our findings may not be comparable due to the differences in the instruments used, a study conducted in the UAE showed low levels of overall awareness on diabetes based on a questionnaire covering definition, causes, symptoms and complications; however, a relatively higher awareness of general symptoms and complications was found among participants [25]. A previous study conducted in Qatar demonstrates that the levels of knowledge, attitude, and practice among adult Arab T2D patients were poor as compared to Qatari patients, although the latter group still needs patient-focused education on diabetes and its management $[23,26]$. This highlights that awareness and knowledge of diabetes and its complications can help both the patients and the providers in achieving favorable therapeutic goals. Lastly, outcomes of this study reflect the need for an improved disease-specific information giving, collaborative decision-making and goal-setting such that patients embrace the behavior changes needed to improve outcomes and will gain the confidence (self-efficacy) to make the most of life regardless of their chronic condition.

\section{Conclusion}

This study highlights various facets of diabetic patients' characteristics, behaviors and understanding of diabetes-related factors influencing self-management of diabetes. Results of the study emphasizes the importance of healthcare information and services received by the patients such as diabetes planning and messaging which significantly contributed to their level of confidence in managing diabetes. Outcome of the study suggests increased patient engagement in diabetes goal setting in partnership with the healthcare professionals to augment their knowledge and develop their confidence in self-managing diabetes. Patients require further education and counselling about risks factors such as smoking, alcohol use and adverse effects of medicines require further education and counselling. Patients were found to be generally satisfied about the level of information and support they received from the healthcare system. Given the burden of diabetes entails a profound need for strong collaboration between patient and healthcare providers for patients to confidently manage their disease. It would be more valuable to further expand diabetes related programs in the country through innovative approaches such as using social media, diabetes hotline number, and health campaigns and events to address diabetes-related concerns.

\section{Acknowledgement}

The authors would like to thank Hamad Medical Corporation, Primary Health Care Corporation and the survey participants for their support in the project.

\section{References}

1. (2018) National Health Strategy. Qatar National Health Strategy 20112016.

2. (2012) Qatar Stepwise Report. p. 72.
3. Al Kuwari HM (2016) Burden of Diabetes. International Diabetes Leadership Forum, Qatar.

4. (2016) Qatar National Diabetes Strategy Preventing Diabetes Together 2016-2022. Ministry of Public Health 2016.

5. Bright R, Sakurada B (2016) A Population Health Strategy for Diabetes: New Partners, New Opportunities. National Academy of Medicine.

6. Cochran J, Conn VS (2008) Meta-analysis of quality of life outcomes following diabetes self-management training. Diabetes Educator 34(5): 815-823.

7. Worswick J, Wayne SC, Bennett R, Fiander M, Mayhew A, et al. Improving quality of care for persons with diabetes: an overview of systematic reviews - what does the evidence tell us? (2013) Syst Rev 2: 26 .

8. Powers MA, Bardsley J, Cypress M, Duker P, Funnell MM, et al. (2016) Diabetes Self-management Education and Support in Type 2 Diabetes: A Joint Position Statement of the American Diabetes Association, the American Association of Diabetes Educators, and the Academy of Nutrition and Dietetics. Clin Diabetes 34(2): 70-80.

9. (2013) Qatar Healthcare Facilities Master Plan 2013-2033.

10. (2017) Qatar in Figures. 32.

11. (2018) Hamad Medical Corporation, Our organization.

12. Al-Thani AA, Farghaly AH, Akram H, Khalifa S, Vinodson B, et al. (2018) Public Awareness and Perceptions about Diabetes in the State of Qatar. Cureus 10(5): e2671.

13. Deshpande AD, Harris-Hayes M, Schootman M (2008) Epidemiology of Diabetes and Diabetes-Related Complications. Phys Ther 88(11): 1254-1264.

14. Elhadd TA, Al-Amoudi AA, Alzahrani AS (2007) Epidemiology, clinical and complications profile of diabetes in Saudi Arabia: a review. Ann Saudi Med 27(4): 241.

15. Cleary PD, McNeil BJ (1988) Patient satisfaction as an indicator of quality care. Inquiry 25(1): 25-36.

16. Ciechanowski PS, Katon WJ, Russo JE, Walker EA (2001) The patientprovider relationship: attachment theory and adherence to treatment in diabetes. Am J Psychiatry 158(1): 29-35.

17. Nam S, Chesla C, Stotts NA, Kroon L, Janson SL (2011) Barriers to diabetes management: patient and provider factors. Diabetes research and clinical practice 93(1): 1-9.

18. Nagelkerk J, Reick K, Meengs L (2006) Perceived barriers and effective strategies to diabetes self-management. J Adv Nurs 54(2): 151-158.

19. Mohamed H, A-Lenjawi B, Amouna P, Zotor F, El Mahdi H, et al. (2015) Knowledge, attitude, and practice of type 2 Arab diabetic patients in Qatar: a cross-sectional study. Int J Diabetes Dev Ctries 35(2): 205-209.

20. Kheir N, Greer W, Yousif A, Al Geed H, Al Okkah R (2011) Knowledge, attitude and practices of Qatari patients with type 2 diabetes mellitus. Int J Pharm Pract 19(3): 185-191.

21. Stone K, Horney JA (2018) Methods: Surveillance. In: Horney JH, (Edt,) Disaster Epidemiology: Methods and Applications, p. 11-23.

22. Frost J, Garside R, Cooper C, Nicky Britten (2014) A qualitative synthesis of diabetes self-management strategies for long term medical outcomes and quality of life in the UK. BMC Health Serv Res 1614: 348.

23. Vahdat S, Hamzehgardeshi L, Hessam S, Hamzehgardeshi Z (2014) Patient Involvement in Health Care Decision Making: A Review. Iran Red Crescent Med J 16(1): e12454.

24. Al-Maskari F, El-Sadig M, Al-Kaabi JM, Bachar Afandi, Nicolas Nagelkerke, et al. (2013) Knowledge, Attitude and Practices of Diabetic Patients in the United Arab Emirates. PLoS ONE 8(1): e52857. 


\section{Current Research in Diabetes \& Obesity Journal}

25. Al Bimani ZS, Khan SA, David P (2015) Evaluation of T2DM related knowledge and practices of Omani patients. Saudi Pharm J 23(1): 2227.

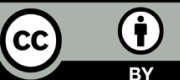

This work is licensed under Creative Commons Attribution 4.0 Licens OI: 10.19080/CRDOJ.2019.09.555761
26. Bodenheimer T, Holman H (2002) Chronic disease self-management in primary care JAMA 288(19): 2469-2475.

\section{Your next submission with Juniper Publishers will reach you the below assets}

- Quality Editorial service

- Swift Peer Review

- Reprints availability

- E-prints Service

- Manuscript Podcast for convenient understanding

- Global attainment for your research

- Manuscript accessibility in different formats

( Pdf, E-pub, Full Text, Audio)

- Unceasing customer service

Track the below URL for one-step submission https://juniperpublishers.com/online-submission.php 